\title{
How does chronic tonsillitis affects anxiety and depression?
}

Ferit AKIL ${ }^{1}$, Serkan DEDEOGLU ${ }^{1}$, Muhammed AYRAL ${ }^{1}$, Muhammed Akif DENiZ², Esref ARAC ${ }^{3}$, Ahmet $^{2}$ UER $^{4}$, Nesreddin Fatih TURGUT ${ }^{5}$

\footnotetext{
${ }^{1}$ Department of Otorhinolaryngology, Diyarbakir Gaziyasargil Education and Research Hospital, Diyarbakir, Turkey

${ }^{2}$ Department of Radiology, Diyarbakir Gaziyasargil Education and Research Hospital, Diyarbakir, Turkey

${ }^{3}$ Department of Internal Medicine, Diyarbakir Gaziyasargil Education and Research Hospital, Diyarbakir, Turkey

${ }^{4}$ Department of Psychiatry, Afyon Kocatepe University, Afyon, Turkey

${ }^{5}$ Department of Otolaryngology, Artvin State Hospital Artvin, Turkey
}

\section{$S U M M A R Y$}

Chronic/recurrent tonsillitis is a condition that affects the quality of life with symptoms such as pain, fever, halitosis, and so forth. However, the effect of this condition on depression and anxiety has not been studied. Therefore, this study aimed to investigate the complex relationship between chronic/recurrent tonsillitis and depression and anxiety in adult patients.

The study included 60 female and 60 male patients and 25 healthy male and 25 healthy female controls, aged 18 -40 years. The participants were made to fill out the Beck depression and anxiety inventories (BDI and BAI). Those who met the inclusion criteria were included. The averages and cutoff values of the total scores were investigated separately for males and females.

For both males and females, the averages of total BDI scores $(P<0.043$ and $<0.035$, respectively) and total BAI scores $(P$ $=0.019$ and 0.027 , respectively) were significantly higher in group 2 than in group 1 .

This study was novel in exploring the relationship between chronic/recurrent tonsillitis and depression and anxiety in adults. The findings of this study might enhance the understanding on this subject and serve as a valuable guidance for the interested researchers.

Key words: Adult, anxiety, depression, tonsillitis

\section{INTRODUCTION}

Chronic/recurrent tonsillitis is a persistent inflammation of the tonsils due to recurrent acute or subclinical infections. During acute tonsillitis, infection may persist in the fibrous tissue and cause another tonsillitis attack after days or weeks if proper antibiotic treatment is not provided for a sufficient time. Furthermore, inflammatory scrapings inside the crypts may cause subclinical infection and subsequent tonsillitis attacks (1). Generally, a diagnosis of chronic/recurrent tonsillitis is based on tonsillitis or throat pain that recurs three to four times a year and does not respond to sufficient antibiotic treatment (2). A recurrent throat pain is generally accompanied by fever, weakness, and arthralgia. Secondary foul breath (halitosis) that fills tonsil crypts may also be present $(3,4)$. Chronic tonsillitis is in fact an adult disease; however, it can be observed at all ages. Like any other chronic disease, tonsillitis can also trigger psychological disorders. Numerous studies on the relationship between chronic/recurrent tonsillitis in adults and psychological disorders and quality of life are available, whichcompare the quality of life of patients before and after surgery (5) or investigate the quality of life and mental health in pediatric patients (6). This study sought to understand the complex relationship between depression and anxiety and chronic/ recurrent tonsillitis in adult patients, which was probably related to various psychiatric disorders owing to its symptoms (pain, weakness, fever, and halitosis).

\section{Correspondence:}

Ferit AKIL

Diyarbakır Gaziyaşargil Eğitim ve Araştırma Hastanesi, Kulak-Burun-Boğaz Bölümü, Diyarbakır, Türkiye.

e-mail: feritakil@gmail.com 


\section{MATERIALS AND METHOD}

Inclusion criteria

The study was planned as a prospective analysis of patients with chronic/recurrent tonsillitis referred to the Selahaddin Eyyubi State Hospital between March 2015 and April 2016. The patients were asked to fill out the Beck depression and anxiety inventories (BDI and BAI), and their total scores were analyzed. Literate, notpregnant patients, who were aged 18-40 years, had no chronic and psychiatric disease, and did not use continuous medication, were included in this study. A total of 60 male and 60 female patients and 25 healthy male and 25 healthy female controls were analyzed. This control group consisted of age- and educationmatched healthy individuals. The sample group was divided into two groups for males and females, and these groups were analyzed individually. For both genders, group 1 contained healthy individuals, whereas group 2 contained patients with chronic/ recurrent tonsillitis. An ethical unit approval was obtained from the Selahaddin Eyyubi State Hospital.

\section{Psychiatric assessment}

The severity of depression was assessed using BDI, which was a 21-item self-report scale developed by Beck et al. (7). Items in this scale were rated from 0 to 3 in increasing order of severity. The item scores were summed up and ranged from 0 to 63 . Higher scores correlated with more severe depression. The pathologic cutoff value for the BDI score was determined to be 17 in the Turkish population, which reflected moderate and severe depressive states $(8,9)$. The validity and accuracy of the BDI in the Turkish population were studied by Hisli et al. (10). Anxiety was measured using the 21-item self-reported BAI (11). Each item was scored from 0 to 3 according to severity. The item scores were summed up, and higher scores indicated higher anxiety levels. The pathologic cutoff value for the BAl score was determined to be 16 in the Turkish population; scores above this value reflected moderate-to-severe anxiety states $(8,9)$. The validity and reliability of the Turkish version of the BAI were studied by Ulusoy et al. (12).

Statistical analyses

Statistical evaluation was carried out using the SPSS 15.0 version (SPSS Inc., IL, USA). Variables were compared using the Student's t test. The total BDI and BAI scores and the number of patients and control individuals with higher or lower scores than the pathological cutoff values (1) were analyzed and compared. Males and females were analyzed separately.

\section{RESULTS}

\section{Males}

The average age was $27 \pm 8$ years in group 1 and $29 \pm 12$ years in group 2 , with no statistically significant difference $(P<0.231)$. The average of total scores obtained from the BDI was $10 \pm 7$ in group 1 and $14 \pm 6$ in group 2 . The average of total scores from this inventory was significantly higher in group 2 compared with group 1 ( $P<$ 0.043). Two individuals from group 1 and seven individuals from group 2 obtained higher scores than the pathological cutoff value in the BDI. The difference observed in the numbers of individuals who obtained higher scores than the cutoff value in the BDI was not significant $(P<0.076)$. The average of total scores in the BAl was 11 \pm 5 in group 1 and $15 \pm 6$ in group 2. The difference between the average of total scores in the two groups was statistically significant $(P<0.019)$. One individual from group 1 and four individuals from group 2 obtained higher scores than the pathological cutoff value in the BAl. The numbers of individuals who obtained higher and lower scores than the cutoff value in the BAl were not significantly different between the two groups $(P<0.065)$.

\section{Females}

The average age was $29 \pm 11$ years in group 1 and $32 \pm 8$ years in group 2, with no statistically significant difference ( $P<0.107)$. The average total scores obtained in the BDI was $9 \pm 8$ in group 1 and $13 \pm 5$ in group 2. The average of total scores from this inventory was significantly higher in group 2 compared with group $1(\mathrm{P}<$ 0.035). Two individuals from group 1 and six individuals from group 2 obtained higher scores than the pathological cutoff value in the $\mathrm{BDI}$. The difference observed in the numbers of individuals who obtained higher scores than the cutoff value in the BDI was not significant $(P<0.191)$. The average of total scores from the BAl was $10 \pm 6$ in group 1 and $13 \pm 7$ in group 2 . The difference between the average of total scores in the two groups was statistically significant $(P<0.027)$. One individual from group 1 and five individuals from 
TABLE 1: Causes of hyperprolactinemia.

\begin{tabular}{|c|c|c|c|c|c|c|}
\hline & $\begin{array}{l}\text { Male group } 1 \\
\text { average }\end{array}$ & $\begin{array}{l}\text { Male group } 2 \\
\text { average }\end{array}$ & $P$ value & $\begin{array}{c}\text { Female group } 1 \\
\text { average }\end{array}$ & $\begin{array}{c}\text { Female group } 2 \\
\text { average }\end{array}$ & $P$ value \\
\hline BDI total scores & $10 \pm 7$ & $14 \pm 6$ & 0.043 & $9 \pm 8$ & $13 \pm 5$ & 0.035 \\
\hline Beck depression cutoff value & 0.080 & 0.087 & 0.076 & 0.080 & 0.075 & 0.191 \\
\hline BAl total scores & $11 \pm 5$ & $15 \pm 6$ & 0.019 & $10 \pm 6$ & $13 \pm 7$ & 0.027 \\
\hline Beck anxiety cutoff value & 0.040 & 0.050 & 0.065 & 0.040 & 0.062 & 0.057 \\
\hline
\end{tabular}

group 2 obtained higher scores than the pathological cutoff value in the BAl. The numbers of individuals who obtained higher and lower scores than the cutoff value in the BAl were not significantly different between the two groups $(P<0.057)$ (Table 1$)$.

\section{DISCUSSION}

Databases PubMed, Medline, and Google Scholar were searched using the key words tonsillitis and depression, tonsillitis and anxiety, tonsillitis and Beck depression, and Beck anxiety, but no study on the relationship between chronic/recurrent tonsillitis and anxiety and depression was found. Thus, this study was novel in investigating the complex relationship between chronic/ recurrent tonsillitis and depression and anxiety in adult patients using the BDI and BAI. The studies focusing on the effect of the quality of tonsillectomy on the number of adult patients with chronic/recurrent tonsillitis were analyzed. Removal of the symptoms of recurrent/chronic tonsillitis through tonsillectomy was shown to positively affect the quality of life of the patients $(13,14)$.

In this study, although the average of total scores obtained in the BDI and BAI waas significantly higher in group 2 than in group 1 in males $(P<0.043$ and $<0.019$, respectively), the number of patients who obtained higher scores than the pathological cutoff value was not significantly different in both groups $(P<0.076$ and $<0.065$, respectively).

In females, the average of total scores obtained in the BDI and $B A I$ were significantly higher in group 2 than in group $1(P<$ 0.035 and $<0.027$, respectively); however, the number of patients who obtained higher scores than the pathological cutoff value was not statistically different in the two groups $(P<0.191$ and $<0.057$, respectively).

The results of this study suggested that chronic/recurrent tonsillitis affected both depression and anxiety. However, as the number of patients who obtained higher scores than the pathological cutoff value of the Turkish population was not different in the patient and control groups for both sexes, chronic/recurrent tonsillitis alone could not be classified into depression and/or anxiety disorders, and additional factors were needed to do so.

In 2012, Harry et al. (13) demonstrated that 1 year after undergoing tonsillectomy, patients improved in many parameters related to anxiety and depression, such as physical status, emotional status, general health, mental health, and social functioning.

Richards et al. (14) showed that patients with chronic/ recurrent tonsillitis had statistically significant differences in the improvement in their quality-of-life parameters after tonsillectomy.

Similarly, Schwentnera et al. (5) reported that tonsillectomy provided a significant positive effect on the quality of life of patients with chronic/recurrent tonsillitis.

Additionally, in the studies of Senska et al. (15) and Baumann et al. (16), the quality of life of patients with chronic/recurrent tonsillitis improved significantly after tonsillectomy.

Although these studies demonstrated the effect of tonsillectomy on the quality of life of the patients, this significant improvement was thought to be due to the removal of the symptoms of the disease that disturbed the quality of life of patients with 
recurrent/chronic tonsillitis. The results of this study highlighted the effect of tonsillitis on anxiety and depression, as suggested by several other previous studies.

\section{CONCLUSIONS}

This study was novel in focusing on the relationship between chronic/recurrent tonsillitis and depression and anxiety. The findings of this study might enhance the understanding on this subject using larger patient samples and serve as a valuable guidance for the interested researchers.

\section{REFERENCES}

1. Tekat A. Oral Kavite ve Farenks Enfeksiyonları. In: Onur Ç, eds. Kulak Burun Bogaz Hastalıkları ve Bas Boyun Cerrahisi, ed 1 Turgut, p 545-552, 2002.

2. Burton MJ, Isaacson G, Rosenfeld RM. Extracts from The Cochrane Library: Tonsillectomy for chronic/recurrent acute tonsillitis. Otolaryngol Head Neck Surg 2009;140(1):15-8.

3. Kornblut AD. Non-neoplastic diseases of the tonsils and adenoids. In: Paparella MM, Shumich DA, eds. Otolaryngology, ed 3. Philadelphia: WB Saunders, p 2129-2147, 1991.

4. Wiatrak BJ, Woolley AL. Pharyngitis and adenotonsillar disease. In: Cummings CW, Fredrickson JM, Schuller DE, eds. Otolaryngology Head and Neck Surgery, ed 3. Mosby, p 188215, 1998.

5. Schwentner, Ilona, et al. "Impact of tonsillectomy on quality of life in adults with chronic tonsillitis." Swiss medical weekly 137.31-32 (2007): 454.

6. Georgalas, Christos, Neil Tolley, and Jeevendra Kanagalingam. Measuring quality of life in children with adenotonsillar disease with the Child Health Questionnaire: a first UK study. The Laryngoscope 114.10 (2004): 1849-1855.
7. Beck AT, Ward $\mathrm{CH}$, Mendelson M, Mock J, Erbaugh J. An inventory for measuring depression. Arch Gen Psychiatry. 1961;4:561-71.

8. Vural M, Satiroglu O, Akbas B, Goksel I, Karabay O. Coronary artery disease in association with depression or anxiety among patients undergoing angiography to investigate chest pain. Tex Heart Inst J 2009;36(1):17-23.

9. Ünal FE, Determining the frequency of depression and anxiety and investigating the sociodemographic factors in Bakirköy Dr. Sadi Konuk Training and Research Hospital intern doctors. Specialty Thesis, Bakirköy Dr. Sadi Konuk Training and Research Hospital, İstanbul; 2008

10. Hisli N. Validity and accuracy of Beck depression inventory among university students (In Turkish). Psikoloji Dergis 1989;7(23):3-13.

11. Beck AT, Epstein N, Brown G, Steer RA. An inventory for measuring clinical anxiety: psychometric properties. J Consult Clin Psychol 1988;56(6):893-7.

12. Ulusoy M, Sahin NH, Erkmen H. Turkish version of the Beck Anxiety Inventory: psychometric properties. J Cogn Psycother Int Q 1998;12(2):163-72.

13. Powell, Harry RF, et al. Improved quality of life in adults undergoing tonsillectomy for recurrent tonsillitis. Is adult tonsillectomy really a low priority treatment?. European Archives of Oto-Rhino-Laryngology 269.12 (2012): 2581-2584.

14. Richards, Amanda L., et al. "Quality-of-life effect of tonsillectomy in a young adult group." Anz Journal of Surgery 77.11 (2007): 988-990.

15. Senska G, Ellermann S, Ernst S, Lax H, and Dost P. Recurrent tonsillitis in adults: quality of life after tonsillectomy. Deutsches Ärzteblatt International 2010;107(36):622.

16. Baumann I, Kucheida H, Blumenstock G, Zalaman IM, Maassen MM, Plinkert PK: Benefit from tonsillectomy in adult patients with chronic tonsillitis. Eur Arch Otorhinolaryngol 2006; 263: 556-9. Epub 2006, Feb 21. 